\title{
Intestinal protozoa in diarrheic children in an Egyptian rural area: Role of water contamination and other possible risk factors
}

\author{
Original \\ Article \\ Naglaa F. Abd Ellatif, Mustafa A. Mohamed, Hend A. El-Taweel, Mohamed H. \\ Hamam, Mokhtara N. Saudi
}

Department of Parasitology, Medical Research Institute, Alexandria University, Alexandria, Egypt

\begin{abstract}
Background: Poor quality of drinking water has been linked to increased prevalence of diarrheal diseases. Intestinal protozoal infections are potential water borne pathogens. They contribute significantly to the burden of diarrheal diseases. Their transmission dynamics vary considerably among geographic areas.

Objective: The present study investigated protozoal infections in diarrheic children and their relation to protozoal contamination of drinking water and other potential risk factors in two Egyptian villages.

Material and Methods: Stool samples of 150 diarrheic children and 40 drinking water samples collected from the houses of participating children were examined for enteric protozoa. Data on potential risk factors for protozoal infection were recorded.

Results: Protozoa were detected in $62.7 \%$ of faecal samples and in $32.5 \%$ of water samples. Protozoa were not found in water filtered by domestic filters. Protozoal infection was significantly more common among children who were drinking water in which protozoan contaminants were detected $(84.6 \%)$ compared to those whose water sources were negative $(22.2 \%)$. Multivariate logistic regression analysis revealed that only two factors were independently linked to intestinal protozoal infection among participating children; neglecting hand wash before eating (adjusted OR: 7.446, 95\% CI: 3.113-17.810) and drinking tap water directly without filtration (adjusted OR: 4.653, 95\% CI: 1.82-11.895).

Conclusion: The study provides supportive evidence for the role of contaminated water in human infection. Attention should be paid to ensure safe drinking water supply in developing countries. Simple measures such as water filtration coupled with personal hygiene can markedly reduce the risk of infection.
\end{abstract}

Key Words: Children, diarrhea, drinking water, intestinal protozoa

Received: 1 December 2017, Accepted: 26 January 2018

Corresponding Author: Naglaa F. Abdellatif, Tel.: 01224110570, E-mail: dr_naglaafathi@hotmail.com

ISSN: 1687-7942, Vol. 11, No. 2, August 2018.

\section{INTRODUCTION}

Gastrointestinal infections and diarrhea are widespread in developing countries including many tropical regions. Infections of the gastrointestinal tract can be caused by viruses, bacteria, protozoa, helminthes and occasionally fungi ${ }^{[1]}$. The WHO reported that diarrheal disease affected far more individuals than any other illness, even in regions that include high income countries ${ }^{[2]}$. Poor quality of drinking water is one of the factors that have been linked to increased prevalence of diarrheal diseases ${ }^{[3]}$.

Intestinal protozoal infections are generally common worldwide. They represent a major cause of diarrheal diseases especially among children in developing countries $^{[1]}$. Giardia lamblia (G. lamblia) and Entamoeba histolytica (E. histolytica) are the most frequently identified protozoan parasites in stool samples. Cryptosporidium parvum (C. parvum), first described in man in 1976, is now recognized as an important cause of diarrhea in young children and immunocompromized adults ${ }^{[4,5]}$.

Protozoa are cosmopolitan parasites that are shed in large numbers in the feces of infected hosts, may be found in different water supplies, as environmentally resistant cysts or oocysts ${ }^{[6]}$. These mentioned pathogenic protozoa, including Cyclospora cayetanensis (C. cayetanensis) and Isospora spp are potential pathogens that have been associated with waterborne infections and water related diarrhea outbreaks ${ }^{[7]}$.

The transmission dynamics of enteric protozoa vary considerably among geographic areas ${ }^{[1]}$. Understanding the significance of different sources of infection is needed 
to set priorities for control. The present study investigated protozoal infections in diarrheic children and its relation to protozoal contamination of drinking water and other possible risk factors in two Egyptian villages.

\section{MATERIAL AND METHODS}

Study design and setting: This cross sectional study was conducted in two Egyptian villages; Abo-Seefa and Kafr-Ziada, located in the Nile Delta in EL-Behera Governorate $88 \mathrm{Km} 88 \mathrm{Km}$ from Alexandria. All houses in the two villages have access to piped water supply connected to the local drinking water network. Diarrheic children attending the local rural health units in the period from February to September 2016, were enrolled in the study. The children were all pre-school and school aged (2-10 years) as in this age group they are more susceptible and have the highest rate of morbidity because of intestinal parasites compared with other ages ${ }^{[8,9]}$. After obtaining an informed consent from parents/guardians of children, an interviewing questionnaire was used to collect demographic and medical data as well as information on factors that might be associated with exposure to protozoal infection and including the domestic source of drinking water whether it was direct tap water or household filtered water. Drinking water samples were collected from the domestic source using clean containers which were labeled immediately after sampling and brought to the laboratory in ice boxes for examination within $24 \mathrm{hrs}$. Stool samples were collected in labeled clean plastic containers, transported to the laboratory where they were divided into two parts: one was used for saline and iodine wet mounts and the other part was preserved in $10 \%$ formalin for concentration and permanent staining ${ }^{[10]}$.

Sample size calculation: Based on $17 \%$ infection rate for Cryptosporidium and $21 \%$ infection rate for Giardia reported in earlier studies in Egypt ${ }^{[11,12]}$ and with $10 \%$ error, a sample of 150 children ( 75 from each village) was considered adequate for the study. Water samples were collected from the domestic drinking water source of 40 participating children. This sample size was calculated with $10 \%$ error based on Cryptosporidium detection rate of $13.7 \%$ and Giardia detection rate of $11.9 \%$ in water samples examined in a previous study in Egypt ${ }^{[13]}$.

Examination of stool and water samples: Stool samples were examined using saline and iodine wet mounts, formalin ethyl-acatate sedimentation technique and permanent staining with trichrome and modified Ziehl-Neelsen acid fast stains ${ }^{[10]}$. Water samples (10 liters each) were filtered using cellulose acetate membrane filter with 0.8 um pore size. The filter was rinsed with one liter of de-ionized water containing $0.1 \%$ tween 80 elute buffer solution and the resulting suspension was washed and concentrated by centrifugation ${ }^{[14]}$. The sediment was examined by saline and iodine wet mounts as well as trichrome and modified Ziehl-Neelsen stains.
Statistical analysis: Data were analyzed using IBM SPSS software package version 20.0 (Armonk, NY: IBM Corp). Comparison of frequencies among groups was performed using Chi-square or Fisher's exact test. A $P$ value less than 0.05 was considered statistically significant. Univariate analysis was used to identify variables associated with protozoal infection among diarrheic children. Odds ratio (OR) and 95\% confidence interval (CI) were calculated to determine the ratio of the odds of an event in one risk group to the odds in the non- risk group. Multivariate logistic regression analysis was performed to calculate adjusted OR and to identify independent risk factors where all variables that were significant in the univariate analysis were included in the model.

The protocol of the study was approved by the Research Ethics Committee of the Medical Research Institute (MRI), Alexandria University.

Ethical consideration: An informed consent was obtained from parents/guardians of the enrolled children. The protocol of the study was approved by the Research Ethics Committee of the Medical Research Institute (MRI), Alexandria University.

\section{RESULTS}

In Abo-Seefa village, the mean age of participating children was $6.49 \pm 2.88$ years and $64 \%$ were males. In Kafr-Ziada, the mean age was $6.24 \pm 3.15$ years and males constituted $44 / 75(58.7 \%)$ of the sample. The overall percentage of parasitic infection among participating children was $94 / 150(62.7 \%)$ G. lamblia was the most prevalent, $35 / 150(23.3 \%)$, followed by Blastocystis spp., 17/150 (18.0\%). Less common protozoa were Cryptosporidium spp. and Entamoeba complex (histolytica/dispar/moshkovskii), 16/150 (10.6\%) each. The non-pathogenic Entamoeba coli (E. coli) was found in $9 / 150(6 \%)$ children. The least common protozoan parasites were Cyclospora spp. and Dientamoeba fragilis (D. fragilis) (Table 1). Helminthic parasites were less frequently encountered and all helminthes infected children had simultaneous protozoan infection. The overall percentage of parasitic infection was significantly higher in Kafr-Ziada village (72\%) compared to Abo-Saeefa village $(53.3 \%)$, (Table 1).

Protozoan contaminants were detected in 13/40 (32.5\%) drinking water samples from the two villages. Cryptosporidium spp. and $C$. cayetanensis were the most frequent $(4 / 40 ; 10 \%)$, followed by Entamoeba complex (3/40; 7.5\%). Blastocystis spp., G. lamblia and E. coli were also identified, (1/40; 2.5\%). There was no statistically significant difference between the two villages regarding the percentages of different protozoa in water samples (Table 2). All contaminants were found in the samples taken directly from taps $(34 / 40 ; 85 \%)$ but not in filtered tap water (6/40; 15\%). 
Protozoal infection was significantly more common in children drinking water contaminated with protozoa $(11 / 13 ; 84.6 \%)$ compared to children whose water sources were negative $(6 / 27 ; 22.2 \%)$. Protozoal contamination of water was associated with 19.25 higher risk of protozoal infection in diarrheic children (95\% CI: 3.316-111.747), (Table 3).

Univariate analysis of variables associated with intestinal protozoal infection among 150 diarrheic children revealed that four factors were significantly associated with higher risk of infection including residence in KafrZiada village (OR:2.25, 95\% CI: 1.142-4.433), neglecting hand wash before eating (OR: 7.754, 95\% CI: 3.47917.285), contact with animals (OR: 2.51, 95\% CI:1.2665.14) and drinking unfiltered tap water (OR: 4.673, 95\% CI:2.122-10.29). On the other hand, the child age and gender, attending day care centers and exposure to canal water were not associated with increased risk of infection (Figure 1). In the multivariate model (Figure 2), only two factors were independently linked to intestinal protozoal infection; neglecting hand wash before eating (adjusted OR: $7.446,95 \%$ CI: 3.113-17.810) and drinking tap water directly without filtration (adjusted OR: 4.653, 95\% CI: 1.82-11.895).

Table (1): Parasitic infections in the studied diarrheic children

\begin{tabular}{|c|c|c|c|c|c|c|c|}
\hline \multirow{3}{*}{ Parasitic infection } & \multicolumn{6}{|c|}{ Village } & \multirow{3}{*}{$P$ values } \\
\hline & \multicolumn{2}{|c|}{ Abo-Seefa $(n=75)$} & \multicolumn{2}{|c|}{ Kafr-Ziada $(n=75)$} & \multicolumn{2}{|c|}{ Total $(n=150)$} & \\
\hline & No & $\%$ & No & $\%$ & No & $\%$ & \\
\hline No infection & 35 & 46.6 & 21 & 28.1 & 56 & 37.3 & \\
\hline Overall infection ** & 40 & 53.3 & 54 & 72.0 & 94 & 62.7 & $0.018 *$ \\
\hline Total & 75 & $50 \%$ & 75 & $50 \%$ & 150 & $100 \%$ & \\
\hline \multicolumn{8}{|l|}{ Protozoa } \\
\hline G. lamblia & 15 & 20.0 & 20 & 26.6 & 35 & 23.3 & 0.334 \\
\hline Entamoeba complex & 6 & 8.0 & 10 & 13.3 & 16 & 10.6 & 0.290 \\
\hline Blastocystis spp. & 11 & 14.6 & 16 & 21.3 & 27 & 18.0 & 0.288 \\
\hline D. fragilis & 0 & 0.0 & 1 & 1.3 & 1 & 0.6 & 1.000 \\
\hline C. cayetanensis & 0 & 0.0 & 2 & 2.6 & 2 & 1.3 & 0.497 \\
\hline Cryptosporidium spp. & 7 & 9.3 & 9 & 12.0 & 16 & 10.6 & 0.597 \\
\hline E. coli & 6 & 8.0 & 3 & 4.0 & 9 & 6.0 & 0.494 \\
\hline $\begin{array}{l}\text { Total protozoal } \\
\text { infections }\end{array}$ & 45 & 60 & 61 & 81.3 & 106 & 70.7 & \\
\hline \multicolumn{8}{|l|}{ Helminths } \\
\hline E. vermicularis & 0 & 0.0 & 1 & 1.3 & 1 & 0.6 & 0.497 \\
\hline H. nana & 1 & 1.3 & 1 & 1.3 & 2 & 1.3 & 1.000 \\
\hline A. lumbricoides & 2 & 2.6 & 2 & 2.6 & 4 & 2.6 & 1.000 \\
\hline Ancylostoma spp. & 1 & 1.3 & 1 & 1.3 & 2 & 1.3 & 1.000 \\
\hline S. mansoni & 0 & 0.0 & 1 & 1.3 & 1 & 0.6 & 0.497 \\
\hline $\begin{array}{l}\text { Total helminthes } \\
\text { infections }\end{array}$ & 4 & 5.4 & 6 & 8 & 10 & 6.7 & \\
\hline
\end{tabular}

* Statistically significant $(P<0.05)$

**Some children were infected with more than one parasite 
Table 2: Protozoan contaminants in drinking water samples.

\begin{tabular}{|c|c|c|c|c|c|c|c|}
\hline \multirow{3}{*}{ Intestinal protozoa } & \multicolumn{6}{|c|}{ Village } & \multirow{3}{*}{ P values } \\
\hline & \multicolumn{2}{|c|}{$\begin{array}{c}\text { Abo-Saeefa } \\
(\mathbf{n}=\mathbf{2 0})\end{array}$} & \multicolumn{2}{|c|}{$\begin{array}{c}\text { Zafr-Ziada } \\
(\mathrm{n}=\mathbf{2 0})\end{array}$} & \multicolumn{2}{|c|}{$\begin{array}{c}\text { Total } \\
(\mathrm{n}=\mathbf{4 0})\end{array}$} & \\
\hline & No. & $\%$ & No. & $\%$ & No. & $\%$ & \\
\hline Total & 7 & 35 & 6 & 30 & 13 & 32.5 & 0.736 \\
\hline Entamoeba complex & 2 & 10 & 1 & 5 & 3 & 7.5 & 1.000 \\
\hline G. lamblia & 0 & 0 & 1 & 5 & 1 & 2.5 & 1.000 \\
\hline Blastocystis spp. & 0 & 0 & 1 & 5 & 1 & 2.5 & 1.000 \\
\hline C. cayetanensis & 2 & 10 & 2 & 10 & 4 & 10 & 1.000 \\
\hline Cryptosporidium spp. & 3 & 15 & 1 & 5 & 4 & 10 & 0.620 \\
\hline E. coli & 0 & 0 & 1 & 5 & 1 & 2.5 & 1.000 \\
\hline
\end{tabular}

E. coli and Cryptosporidium spp. were detected simultaneously in one water sample in Kafr-Ziada

Table 3: Protozoal contamination of drinking water samples and the corresponding infection in diarrheic children

\begin{tabular}{|c|c|c|c|c|c|c|c|c|c|}
\hline \multirow{3}{*}{ Water contamination } & \multicolumn{5}{|c|}{ Protozoal infection } & \multirow{3}{*}{$P$ values } & \multirow{3}{*}{ OR } & \multirow{2}{*}{\multicolumn{2}{|c|}{$95 \%$ CI }} \\
\hline & \multicolumn{2}{|c|}{ Positive } & \multicolumn{2}{|c|}{ Negative } & \multirow{2}{*}{$\begin{array}{c}\text { Total } \\
\text { No. } \\
\end{array}$} & & & & \\
\hline & No. & $\%$ & No. & $\%$ & & & & $\mathbf{L L}$ & UL \\
\hline Positive & 11 & 84.6 & 2 & 15.4 & 13 & & & & \\
\hline & & & & & & $<0.001 *$ & 19.25 & 3.316 & 111.747 \\
\hline Negative $^{R}$ & 6 & 22.2 & 21 & 77.8 & 27 & & & & \\
\hline Total & 17 & 42.5 & 23 & 57.5 & 40 & & & & \\
\hline
\end{tabular}

OR: Odds ratio, CI: Confidence interval, LL: Lower limit, UL: Upper Limit, R: Reference group *: Statistically significant at $P \leq 0.05$.

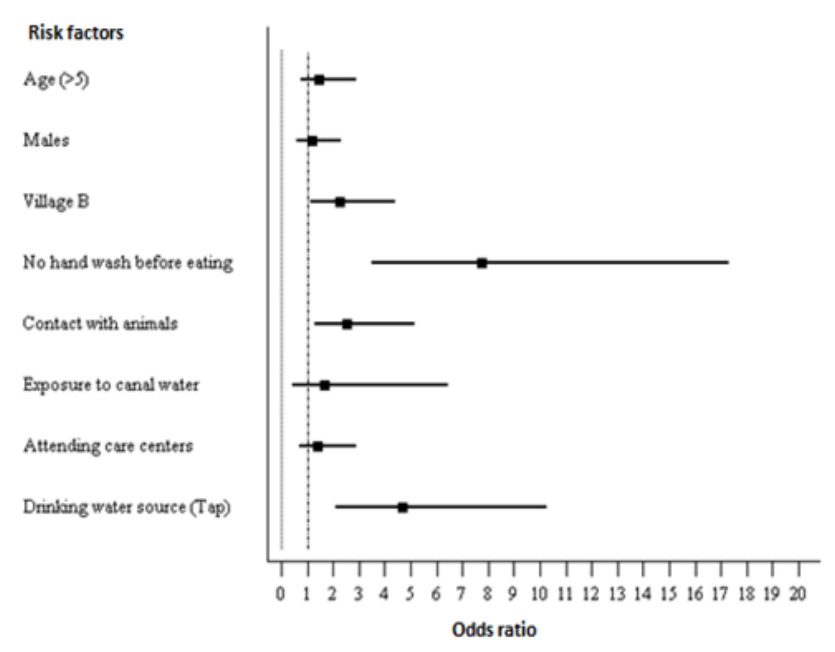

Fig. 1: Forest plot showing univariate analysis of risk factors for protozoal infections among 150 diarrheic children in Abo-Seefa and Kafr-Ziada villages, EL-Behera Governorate.

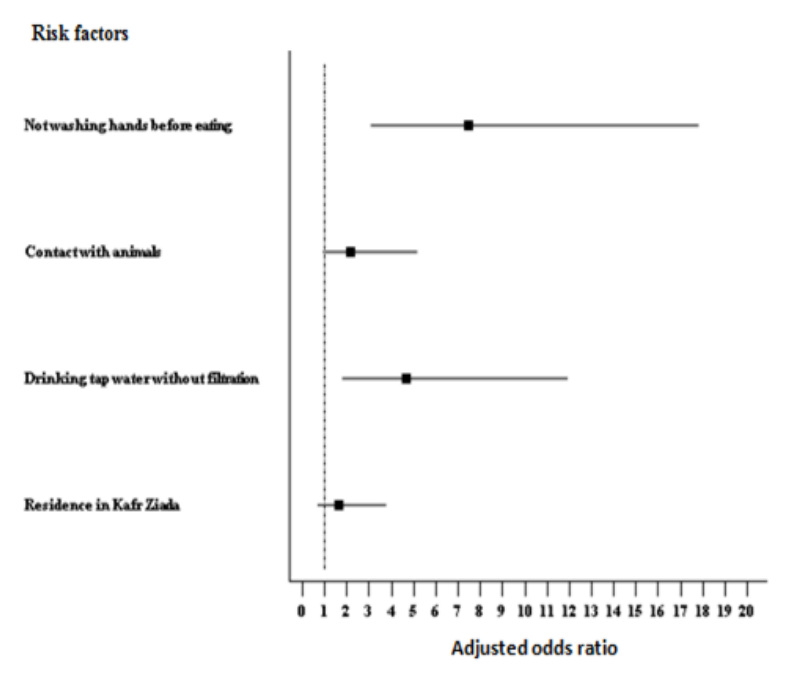

Fig. 2: Forest plot showing logistic regression analysis of risk factors for protozoal infection among 150 diarrheic children in Abo-Seefa and Kafr-Ziada villages, EL-Behera Governorate. 


\section{DISCUSSION}

Enteric protozoa are recognized as an important cause of diarrhea in children. They are potential water borne pathogens that may be found in water bodies due to unsanitary fecal contamination ${ }^{[15]}$. In the current study, $62.7 \%$ of diarrheic children were infected with one or more intestinal protozoa. G. lamblia was the most common, followed by Blastocystis, Entamoeba complex and Cryptosporidium spp. This finding is consistent with previous studies in Egypt confirming an unchanging pattern of intestinal parasitic infection. Mousa et al. in Great Cairo, examined a total of 110 diarrheic stool samples for parasitic causes and found that the overall percentage of parasitic infection was $60.9 \%{ }^{[16]}$. In a study conducted in Damanhur city, El-Behera Governorate, the percentage of parasitic infection among five hundred preschool children was $51.8 \%{ }^{[17]}$.

G. lamblia is the most commonly isolated intestinal parasite throughout the world. Rates of $20-40 \%$ were reported in developing countries, especially in children. An estimated $10 \%$ of the world's population is infected with $E$. histolytica; the highest prevalence is in developing countries with the lowest levels of sanitation ${ }^{[18]}$.

As with the present study, Firdu et al. found that the prevalence rates of $G$. lamblia, Cryptosporidium spp, and Entamoeba complex among children of ages under 13 years with diarrhea in Ethiopia were $15.65 \%, 9.56 \%$, and $4.35 \%$ respectively ${ }^{[19]}$. El-Helaly et al. reported that the percentage of Cryptosporidium infection among children in the age group from 1 to 5 years in Cairo was $11.3 \%{ }^{[20]}$.

Other studies recorded higher infection rates of different parasites. Koffi et al., in central Côte d'Ivoire reported that the species specific prevalence among children under five years was $36.93 \%$ for C. parvum and $22.55 \%$ for E. histolytica ${ }^{[21]}$. Idris et al. reported that Blastocystis spp. comprised the largest proportion of parasites (96\%) identified in diarrheic children mostly aged one to five years in Indonesia ${ }^{[22]}$. These variations in the percentages of parasitic infection may reflect difference in place, socioeconomic, and environmental housing conditions, education and personal hygienic care.

In the present study, enteric waterborne protozoa were identified in $13 / 40(32.5 \%)$ of the collected tap water samples with the coccidian parasites, Cryptosporidium spp. and $C$. cayetanensis being the most frequently isolated, 4/40 (10\%) each; followed by Entamoeba complex 3/40 (7.5\%). G. lamblia, Blastocystis spp. and E. coli were also identified, each in one sample (2.5\%).

Cryptosporidium is more resistant than other pathogens to disinfectants ${ }^{[23]}$. It is not easily removed by physical processes due to its small size and there is some evidence that it survives longer than other protozoa in water environments. It has been used as a reference pathogen for risk assessment of drinking water contamination by protozoan pathogens where its elimination ensures control of all other similar protozoa of concern ${ }^{[15]}$.

In Egypt, protozoal contamination of drinking water was previously reported with variable rates. In northern part of El-Minia Governorate, out of 48 tap water samples, six $(12.5 \%)$ were contaminated with Cryptosporidium oocysts $^{[24]}$. In El-Ismailia city, only two out of 64 tap water samples from four districts were positive for Cryptosporidium oocysts with a mean concentration of 25 oocysts/L. Positive samples were found in only one district suggesting that contamination may have occurred due to leakage of oocysts into the distribution system after treatment ${ }^{[25]}$.

In a recent study in Gharbiya Governorate, of 36 tap water samples examined for protozoan contaminants, Giardia cysts were found in eight samples and Cryptosporidium oocysts in 14 samples $^{[12]}$. In a large survey involving 840 potable water samples from seven districts in Dakahlia Governorate, Cryptosporidium spp. and $G$. lamblia were the most common diseaseagents $(3.1 \%$ and $2.1 \%$ respectively). Other protozoan contaminants were E. histolytica (1\%), B. hominis (1\%), Iodamoeba spp., (0.5\%), Isospora belli $(0.47 \%)$, E. coli $(0.36 \%)$ and C. cayetanensis $(0.24 \%)^{[26]}$. In another study in Fayoum Governorate, 95 water samples were collected from different water sources, taps (65) and tanks (30), from 6 districts. All water samples collected from tanks (100\%) were contaminated by protozoa of medical importance, while only $6(9.2 \%)$ of the tap water samples were pathogen free. The overall detection rates of contaminants in water sources were $86.3 \%, 52.6 \%, 13.7 \%$ by free living amoeba, Cryptosporidium spp. and G. lamblia, respectively ${ }^{[27]}$.

In the current studied villages, it was observed that storage of water in roof tanks was used in all houses to overcome intermittence of water supply. Contamination of water may have occurred as a result of inappropriate storage inside the dwellings. Storage of water increases the risk of contamination and reduces the disinfectant residual[ ${ }^{[28,29]}$. However, shortcomings in water treatment and unsatisfactory disinfection at the water treatment plant cannot be excluded.

The ability of enteric protozoa to cause illness even with low infective dose makes protozoal contamination of drinking water a potential public health threat ${ }^{[15,30]}$. The present study revealed a statistically significant association between the detection of protozoan infection in diarrheic children and protozoan contamination of their domestic source of water confirming the role of water in transmission of intestinal protozoa. This finding is consistent with those of Nimri who found Cryptosporidium and Cyclospora oocysts in water storage tanks at homes of six patients who were infected by these parasites but not in tank water of 
non-infected patients ${ }^{[31]}$. In a study conducted in a rural area in Zimbabwe where drinking water is obtained from wells, boreholes or springs and is mostly consumed untreated, high $83 \%$ prevalence of intestinal protozoan infections was reported among the study subjects, and protozoan species were identified microscopically in $11 / 30(36.6 \%)$ water samples examined ${ }^{[32]}$.

In the present study, none of the samples collected after domestic filtration were contaminated by protozoa; while drinking tap water directly, without using filters, was identified as an independent risk factor for protozoal infection in diarrheic children Using household filters has been shown to be a practical and cost effective method for prevention of diarrheal diseases ${ }^{[15,32]}$. In a study in Iran, there was no parasitic contamination in three samples from water-selling stations probably due to appropriate filtration $^{[10]}$. Selecting the most appropriate filter pore size is crucial; a size of one $\mu \mathrm{m}$ or less for the filter media pore is recommended to ensure removal of Cryptosporidium oocysts from water ${ }^{[15]}$. In the present study, it was not possible to record the filter pore size since most users were unaware of the detailed properties of their household filters.

Another variable independently associated with protozoal infection in the current work was neglecting hand wash before eating. Similar results were reported by EL-Masry et al. ${ }^{[33]}$ who showed that hand washing before meals was the most important factor of personal hygienic habits that has significant effect on the rate of intestinal parasitic infections. Mohammad et al. ${ }^{[34]}$ reported that improper hygiene in food handling was a significant risk factor for parasitic infection. Another study by AlMekhlafi et al.$^{[35]}$ found that the practices of not washing hands before eating and not clipping fingernails were significantly associated with a higher likelihood of infections among schoolchildren.

In the present work, a higher percentage of infection was detected among those who were residing in Kafr-Ziada compared to Abo-Seefa village. Though not confirmed in the multivariate model, this may be linked to the low socioeconomic level, lack of sanitation and bad personal hygiene in Kafr-Ziada. On the other hand, Abo-Seefa is characterized by a higher standard of living, better health awareness and availability of medical services.

Some protozoal infections are known to be zoonotically transmitted. The dynamics of zoonotic transmission differ from one geographic area to another ${ }^{[36]}$. Our results revealed that contact with animals was significantly associated with increased risk of protozoal infection in the univariate but not in the multivariate model. Other authors reported that residence in rural areas, contact with animals and poor hygiene are independent variables linked to intestinal parasitosis $^{[16,17]}$.
In the present work, the child age and gender were not associated with increased risk of protozoal infection. This is possibly because of sharing the same environmental and social conditions. While older age groups may have greater exposure due to outdoor feeding and unhygienic toilet practices with less parental supervision, younger children are more vulnerable due to lower immunity ${ }^{[37,38]}$. Males may be more exposed to infection sources as a result of their habits related to playing and other outdoor activities ${ }^{[39]}$.

Close contact of children in day care centers favors anthroponotic transmission of most enteric protozoa unless good hygiene is practiced ${ }^{[40,41]}$. Lack of significant association with protozoal infection in the present study suggests that person to person spread plays a limited role compared to waterborne transmission.

\section{CONCLUSION}

Intestinal protozoal infections predominate among rural diarrheic children, constituting a greater burden than helminthic infections. The observed association between contamination of drinking water by protozoa and their detection in diarrheic children provides a supportive evidence for the role of contaminated water in human infection. Attention should be paid to ensure safe drinking water supply in developing countries. Simple measures such as water filtration coupled with personal hygiene can markedly reduce the risk of infection.

Author contribution: NF AbdEllatif participated in the conception and implementation of work, interpretation of the results, and writing of the manuscript. MA Mohamed conceived and designed the experiments; reviewed the presentation and interpretation of the results. HA El-Taweel participated in the design, conception and implementation of work, interpretation of the results, and writing of the manuscript. MH Hamam collected the stool samples and participated in the implementation of the work. MN Saudi reviewed the presentation and interpretation of the results.

\section{REFERENCES}

1. Fletcher SM, Stark D, Harkness J, Ellis J. Enteric protozoa in the developed world: a public health perspective. Clin Microbiol Rev. 2012; 25: 420-449. 10.1128/CMR.05038-11

2. WHO The global burden of disease: 2004 update. WHO press, Geneva, Switzerland 2008.

3. Levy K. Does poor water quality cause diarrheal disease? Am J Trop Med Hyg 2015; 4; 93: 899-900.

4. Ortega YR, Eberhard ML, Kris H. Protozoan diseases: cryptosporidiosis, giardiasis and other intestinal 
protozoan diseases. In: Heggenhougen K (ed) International encyclopedia of public health. Academic Press, Oxford, United Kingdom,2008 pp 354-366.

5. Farthing MJG, Cevalls AM, Kelly P. Intestinal protozoa. In: Gook GC, Zumla A (eds) Manson's tropical disease, $22^{\text {nd }}$. WB Saunders, London, 2009 pp 1375-1406.

6. Arnone RD, Walling JP. Waterborne pathogen in urban watersheds. J Water Health 2007; 5: 149-162.

7. Rosado-García FM, Guerrero-Flórez M, Karanis G, Hinojosa MDC, Karanis P. Water-borne protozoa parasites: The Latin American perspective. Int J Hyg Environ Hrealth 2017; 220:783-798.

8. Noor Azian MY, San YM, Gan CC, Yusri MY, Nurulsyamzawaty Y, Zuhaizam AH, et al. Prevalence of intestinal protozoa in an aborigine community in Pahang, Malaysia. Trop Biomed. 2007 Jun; 24(1):5562.

9. Ashtiani MT, Monajemzadeh M, Saghi B, Shams S, Mortazavi SH, Khaki S, et al. Prevalence of intestinal parasites among children referred to Children's Medical Center during 18 years (1991-2008), Tehran, Iran. Ann Trop Med Parasitol 2011 Oct;105(7): 507-512.

10. Garcia LS. Diagnostic Medical Parasitology. 5th Ed. ASM Press, Washington. 2007, pp. 581-600

11. Fathy MM, Abdelrazek NM, Hassan FA, El-Badry AA. Molecular copro-prevalence of Cryptosporidium in Egyptian children and evaluation of three diagnostic methods. Indian Pediatr 2014; 51:727-729.

12. Helmy YA, Klotz C, Wilking H, Krücken J, Nöckler $\mathrm{K}$, Von Samson-Himmelstjerna G, et al. Epidemiology of Giardia duodenalis infection in ruminant livestock and children in the Ismailia province of Egypt: insights by genetic characterization. Parasit Vectors 2014; 11; 7:321. 10.1186/1756-3305-7-321

13. El-Kowrany SI, El- Zamarany EA, El-Nouby KA, El-Mehy DA, Abo Ali EA, Othman AA, et al. Water pollution in the Middle Nile Delta, Egypt: An environmental study. J Adv Res 2016; 7: 781-794.

14. Rafiei A, Rahdar M, Nourozi RV. Isolation and identification of parasitic protozoa in sampled water from the southwest of Iran. Jundishapur J Helath Sci 2014; 6(4): e23462

15. WHO. Guidelines for drinking water quality. 4th ed, WHO press, Geneva 2011.
16. Mousa KM, Abdel-Tawab AH, Khalil HH, ElHussieny NA. Diarrhea due to parasites particularly Cryptosporidium parvum in Great Cairo, Egypt. J Egypt Soc Parasitol 2010; 40: 439-450.

17. Hegazy AM, Younis NT, Aminou HA, Badr AM. Prevalence of intestinal parasites and its impact on nutritional status among preschool children living in Damanhur City, El-Behera Governorate, Egypt. J Egypt Soc Parasitol 2014; 44:517-524.

18. Chacon-Cruz E. Intestinal protozoal diseases Available from: http://emedicine.medscape.com/ article/999282-overview. Accessed 10 May 2017

19. Firdu T, Abunna F Girma M. Intestinal protozoal parasites in diarrheal children and associated risk factors at Yirgalem hospital, Ethiopia: A casecontrol study. Int Sch Res Notices 2014; 357126. $10.1155 / 2014 / 357126$

20. El-Helaly NS, Aly MM, Attia SS. Detection of Cryptosporidium infection among children with diarrhea. N Y Sci J 2012; 5: 68-76.

21. Koffi M, N'Djeti M, Konan1 T, Djè3 Y. Molecular characterization of intestinal protozoan parasites from children facing diarrheal disease and associated risk factors in Yamoussoukro, Côte d'Ivoire. Afr J Environ Sci Technol 2014; 8:178-184.

22. Idris NS, Dwipoerwantoro PG, Kurniawan A, Said M. Intestinal parasitic infection of immunocompromised children with diarrhoea: clinical profile and therapeutic response. J Infect Dev Ctries 2010; 4:309-317.

23. Pereira VJ, Marques R, Marques M, Benoliel MJ, Barreto Crespo MT. Free chlorine inactivation of fungi in drinking water sources. Water Res 2013; 1; 47:517-523.

24. Khalifa RM, Ahmad AK, Abdel-Hafeez EH, Mosllem FA. Present status of protozoan pathogens causing waterborne disease in northern part of El-Minia Governorate, Egypt. J Egypt Soc Parasitol 2014; 44:559-566.

25. Rayan HZ, Eida OM, EL-Hamshary EM, Ahmed SA. Detection of human Cryptosporidium species in surface water sources in Ismailia using polymerase chain reaction. PUJ 2009; 2:119-126.

26. EL-Shazly AM, EL-Sheikha HM, Soltan DM, Mohamed KA, Morsy TA. Protozoal pollution of surface water sources in Dekahlia Governorate, Egypt. J Egypt Soc Parasitol 2007; 37:51-64. 
27. Sakran T, El-Shahawy G, Shalaby MA, Sabry HY, Matooq PM, Elmallah AM. Detection rates of waterborne protozoa in water sources from Fayoum Governorate. PUJ 2017;10(1-2):30-38.

28. Sheikhi R, Alimohammadi M, Askari M, Moghaddasian MS. Decay of free residual chlorine in drinking water at the point of use. Iran J Public Health 2014; 43:535-536.

29. Shields KF, Bain RE, Cronk R, Wright JA, Bartram J. Association of supply type with fecal contamination of source water and household stored drinking water in developing countries: A bivariate meta-analysis. Environ Health Perspect 2015; 123:1222-1231.

30. Chappell CL, Okhuysen PC, Langer-Curry R, Widmer G, Akiyoshi DE, Tanriverdi S, et al. Cryptosporidium hominis: experimental challenge of healthy adults. Am J Trop Med Hyg 2006; 75:851-857.

31. Nimri LF. Cyclospora cayetanensis and other intestinal parasites associated with diarrhea in a rural area of Jordan. Int Microbiol 2003; 6:131-135.

32. Mtapuri-Zinyowera S, Ruhanya V, Midzi N, Berejena C, Chin'ombe N, Nziramasanga $\mathrm{P}$, et al. Human parasitic protozoa in drinking water sources in rural Zimbabwe and their link to HIV infection. Germs 2014; 4: 86-91.

33. El-Masry HM, Ahmed YA, Hassan AA, Zaky S, AbdAllah ES, El-Moselhy EA, et al. Prevalence, risk factors and impacts of schistosomal and intestinal parasitic infections among rural school children in Sohag Governorate. Egypt J Hosp Med 2007; 29: 616630.

34. Mohammad KA, Mohammad AA, Abu El-Nour MF, Saad MY, Timsah AG. The prevalence and associated risk factors of intestinal parasitic infections among school children living in rural and urban communities in Damietta Governorate, Egypt. Academia Arena 2012; 4:90-97.
35. Al-Mekhlafi AM, Abdul-Ghani R, Al-Eryani S, Saif-Ali R, Mahdy MA. School-based prevalence of intestinal parasitic infection and associated risk factors in rural communities of Sana'a, Yamen. Acta Trop 2016; 163:135-141.

36. Lal A, Hales S, French N, Baker MG. Seasonality in human zoonotic enteric diseases: a systematic review. PLoS One 2012; 7(4):e31883.

37. Al-Mohammed HI, Amin TT, Aboulmagd E, Hablus HR, Zaza BO. Prevalence of intestinal parasitic infections and its relationship with sociodemographics and hygienic habits among male primary schoolchildren in Al-Ahsa, Saudi Arabia. Asian Pacific J Trop Med 2010; 3: 906-912.

38. OsmanM,ElSafadiD, CianA, BenamrouzS, Nourrisson $\mathrm{C}$, Poirier $\mathrm{P}$, et al. Prevalence and risk factors for intestinal protozoan infections with Cryptosporidium, Giardia, Blastocystis and Dientamoeba among school children in Tripoli, Lebanon. PLoS Negl Trop Dis 2016; 14;10(3):e0004496.

39. Yassin MM, Shubair ME, Al-Hindy AI, Jadallah S. Prevalence of intestinal parasites among school children in Gaza city. J Egypt Soc Parasitol 1999; 29: 365-373.

40. Cañete R, Díaz MM, Avalos García R, Laúd Martinez PM, Manuel Ponce F. Intestinal parasites in children from a day care centre in Matanzas City, Cuba. PLoS One 2012; 7(12):e51394.

41. Oliveira-Arbex AP, David EB, Oliveira-Sequeira TC, Bittencourt GN, Guimarães S. Genotyping of Giardia duodenalis isolates in asymptomatic children attending daycare centre: evidence of high risk for anthroponotic transmission. Epidemiol Infect 2016; 144:1418-1428. 